rathsam sein, bei gerichtlichen Uutersuchungen nicht allein die Schwefelsäure für den Versuch im Marsh'schen Apparal vorher zu reinigen, sondern sie auch frühor arsenfrei für die Bereilung concentrirter Salzsiaure zu machen, wenn dicse letztere durch Oxydation und Zerstörung der organischen Massen mittelst chlorsaurem Kali in Gebrauch kointnt, mit mehr Sicherhoil vielleichl, als dieses durch blofses Wechseln der Absorptionsflüssigkeil bei der Destillation geschehen kann, wo entweder der Punkt der Entfornung des Arsens willkürlich gewählt, oder umständliche Prüfungen ihm vorausgehen miilssen.

\title{
Analyse der unteren Schicht der Lüneburger Infusorienerde.
}

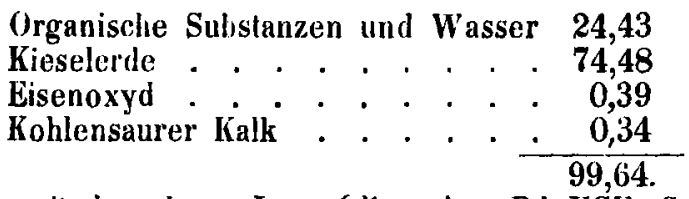

Verglichen mit der oberen Lage (diese Ann. Bd. XCV, S. 292) ergielst sich sin weil grölserer Gehalt an organischen Substanzen und Feuchtigkeil. Lelztere, als nothwendige Lebensbedingung für die Thiere, kann so bedeutend sein, dafs sich die Erde selhst in trockener Jahreszeit wie ein vollgesogener Schwamm ausdrücken läfst. Die untere Schicht enthäll mehr lebende Organismen, als die obere, daher die gröfsere Menge verbrennlicher Substanzen. Abgesehen davon finden wir sie mit vegetabilischen Resten, Wurzelfasern u. s. w. durchwebt. Nach dem Glühen hat die zurückbleibende Kieselerde eine rein weilse Farbe, während die obere Schicht einen rüthlichen Ton - beigemengtes Eisenoxyd blicken läfst.

W. Wicke.

\section{Conservation der Brechweinsleinlösung.}

Die bekanntlich so bald eintretende Zersetzung der Brechweinsteinlösung kann man nach Ed. Harms verliülen, wern man zur Bereitung ein Gemische von Wasser und Alkohol anwendet. Nach ihm soll man das Salz in 50 Theilen Wasser auflösen und 10 T'heile Alkohol zumischen. 1 Drachune dieser Lösung enllält dann 1 Gran Brechweinstein. $W$. 